\title{
RISK ASSESSMENT OF ACUTE UPPER GASTROINTESTINAL HAEMORRHAGE WITH ROCKALL SCORE IN DMCH
}

\author{
MD. NAZRUL ISLAM ${ }^{1}$, MD. SAZEDUR RAHMAN ${ }^{2}$, HUMAYUN KABIR $^{3}, Z^{2}$ HIRUL HUQ ${ }^{4}$, ROBED AMIN $^{5}$, \\ KHAN ABUL KALAM AZAD 6
}

\begin{abstract}
Introduction: Rockall score is used for risk assessment in acute upper gastrointestinal haemorrhage for intervention and prediction for risk of rebleeding and mortality.

Methods: This is a cross sectional hospital based observational study carried out among patients presented with haematemesis with or without melaena in the department of Medicine, Dhaka Medical College Hospital from April, 2013 to March 2014 in one hundred consecutive cases. Rockall score done before and after endoscpy.

Results:Patients mean age found $45.12 \pm 14.9$ years with 4:1 male to female ratio. Service holder were (26.0\%) and 91.0\% were married. Almost half (48.0\%) was educated. Combined haematemesis and melaena was presenting feature in $62.0 \%$ patients among them $72.0 \%$ arrived in hospital within 24 hours of onset. Comorbidity was found in $42.0 \%$ cases and 13\% took NSAID. Oesophageal varix was found in $25.0 \%$. No death observed in $18 \%$ haematemesis patients, one died from melaena (1 of 5) but most died (4 out of 5) from combined haematemesis and melaena. All the 5 death occurred in $89 \%$ rebleeding cases. No death observed in 34\% patients having pre endoscopic Rockall Score d" 2; as well as in 44\% cases post endoscopic Rockall score d" 5 score. Mean duration Hospital stay was $6.36 \pm 4.5$ days.
\end{abstract}

Conclusions: Rockall score is useful in predicting outcomes in acute upper gastrointestinal haemorrhage.

Received: 09 July 2017

DOI: http://dx.doi.org/10.3329/bjmed.v29i1.35403

Accepted: 28 November 2017

\section{Introduction}

Upper gastrointestinal haemorrhage (UGIH) is deûned as bleeding proximal to the ligament of Treitz. Acute UGIH is a common, potentially life threatening condition responsible for more than 300,000 hospital admissions and about 30,000 deaths per annum in America ${ }^{1}$. Treating and preventing acute UGIH costs many billion dollars per annum ${ }^{2}$.

The annual incidence of hospitalization for acute UGIH is 1 per 1000 people in America ${ }^{3}$. It has a mortality of $7 \%$ to $10 \%$. The mortality has decreased only minimally during the last 30 years, despite the introduction of endoscopic therapy that reduces the rate of rebleeding ${ }^{4}$ from increasing percentage of acute UGIH occurring in the elderly, because of their frequent use of antiplatelet medications or anticoagulants, and their frequent comorbid conditions ${ }^{5,6}$. About $45 \%$ of patients now hospitalized for acute UGIH are more than 60 years old ${ }^{7}$. Endoscopic therapy has, however, led to a recent decrease in the need for blood transfusions or surgery for acute $\mathrm{UGIH}^{1}$. The mortality of acute UGIH is much higher for patients who bleed after hospital admission than for those admitted for gastrointestinal bleeding ${ }^{1,8}$.

Exact incidence of acute UGIH in Bangladesh is not known. But Chronic liver disease and Peptic ulcer

1. Senior Consultant, Medicine, General Hospital Narayanganj

2. Junior Consultant, Medicine, General Hospital Narayanganj

3. Senior Consultant, Medicine, General Hospital Netrokona

4. Senior Consultant, Medicine, General Hospital Kishoreganj

5. Associate Professor of Medicine, $\mathrm{DMCH}$

6. Professor and Head of department of Medicine, DMCH

Address of Correspondence: Dr. Md. Nazrul Islam, Senior Consultant, Medicine, General Hospital Narayanganj

Bangladesh J Medicine 2018; $29: 13-25$ 
diseases are two of top ten diseases $(1048+660)$, which are the two main cause of acute UGIH, admitted in $\mathrm{DMCH}$. According to DMCH year book 2011, a total of 33,226 patients admitted in the department of medicine in $\mathrm{DMCH}$, out of which 1708 or $5.14 \%$ patient admitted due to the above mentioned diseases, predicting a large number of population have acute UGIH in our country.

Peptic ulcer disease (PUD) accounts for about half of all the acute $\mathrm{UGIH}^{1,7}$. Major risk factors for PUD include Helicobacter pylori infection, use of nonsteroidal antiinûammatory drugs (NSAIDs) or aspirin, smoking, alcoholism, and prior history of PUD $^{9,10}$. Patients who bleed after admission for another problem usually have $\mathrm{PUD}^{8}$. One study suggests a recent moderate decrease in PUD as a cause of acute UGIH, despite a marked increase in the proportion of elderly patients who have acute UGIH from PUD related to NSAIDs ${ }^{3}$. PUD surgery is performed less than previously, but increasingly bariatric surgery causes postoperative bleeding ulcers $^{11}$. Variceal haemorrhage accounts for about 10 to $25 \%$ of acute UGIH, depending on the catchment area $^{1,7}$. Other relatively common causes of acute UGIH are inûmmatory lesions of the upper gastrointestinal tract, Mallory-Weiss tears, angiodysplasia, and Dieulafoy lesions ${ }^{3,12}$. Postprocedural bleeding is usually related to endoscopic biopsy or therapy ${ }^{13}$.

NICE practice guideline for management of acute upper gastrointestinal bleeding recommended immediate risk assessment using either pre endoscopic Rockall scoring at first assessment and the full Rockall (1996) scoring system after endoscopy or Blatchford (2000) scoring system ${ }^{14}$. Risk stratification scores predict the need for intervention, risk of rebleeding, and risk of mortality.

The Rockall score is developed to determine the risk of rebleeding and death from an episode of acute upper gastrointestinal bleeding ${ }^{14}$. This score is based on the patient's age, presence of shock, coexisting illness, diagnosis, and stigmata of hemorrhage. Therefore, for the complete Rockall score calculation, the endoscopy must be performed. Patients with a score of 2 or below are at low risk of rebleeding and death. Effectiveness of Rockall scoring system is studied in several countries in Europe ${ }^{16}$, Asia ${ }^{17}$, and America $^{18}$. They found Rockall scoring system is very effective in predicting death from acute UGIH. Those with low scores can be managed in outpatient, whereas those with higher scores are admitted and treated in hospital. It has also been used to determine the need for intervention and the risk of mortality ${ }^{19}$.

This study is intended to assess the pre endoscopic and post endoscopic Rockall score among the patients presented with acute upper gastrointestinal haemorrhage in our setting. This study is believed to reveal the pattern of presentation belonging to different risk stratification of Rockall score. It would provide us the relationship between severities of acute upper GI haemorrhage with etiology, age, haemodynamic status and thus would enable us to compare the scenario of our population with that of the western world.

\section{Methods}

This is a cross sectional hospital based observational study that was carried out among the adult patients admitted in department of medicine of $\mathrm{DMCH}$ with haematemesis and/or melaena which is indicated by the patient or relatives or by transferring doctor. All consecutive patients admitted with acute upper gastrointestinal bleeding meeting the inclusion and exclusion criteria was enrolled in the study.

After admission of the patient, duty physician of corresponding unit assessed and managed the patient according to the unit consultant advice. The principal investigator evaluated the patient for enrollment but did not intervene in any management procedure. Patient with chronic UGIH, septicaemia, bleeding abnormality, epistaxis, gum bleeding or receiving anticoagulant was excluded from the study.

Patient evaluation was done clinically for the features and comorbidity mentioned in Rockall scoring table like shock, Ischaemic Heart Disease, Congestive Cardiac failure, liver failure, Renal failure and information from patient/ relatives for metastatic cancer. Pre endoscopic risk assessment with Rockall scoring system was done immediately.

Data regarding personal, demographic profile and clinical information regarding haematemesis and/ or melaena was recorded in a structured case record form including Rockall score table. Complete Rockall score needs endoscopy of upper GIT. Endoscopy of upper GIT was done within 24 hours in department of Gastroenterology of $\mathrm{DMCH}$, in most cases. But in very severe bleeding - manifested by shock, large amount of fresh blood in vomitus or clotted blood, urgent endoscopy was done within 6 
hours in the view of endoscopic intervention for bleeding control.

Follow up was done in every enrolled patient daily for rebleeding, other clinical parameters of general wellbeing, up to final disposal - discharge, referral to surgery or death. 24 hours after admission haematemesis and/or melaena re evaluation was done. Duration of hospital stay, required blood transfusion and outcome of the study subject was documented in the record form. Risk assessment by Rockall score was evaluated against the outcome of each study subject and any abnormal association of predicting factors with higher Roockall score and consequent outcome in our population was sought.

\section{Statistical analysis:}

Statistical analyses were carried out by using the Statistical Package for Social Sciences version 16.0 for Windows (SPSS Inc., Chicago, Illinois, USA). Continuous variables were expressed as mean, standard deviation, and categorical variables as frequencies and percentages. The differences between groups was analyzed by unpaired t-test or chi-square $\left(\chi^{2}\right)$ test and shown with cross tabulation and also the Pearson correlation coefficient was used for testing associations. The relationships between demographic variables with clinical variables were assessed by multiple logistic regression analysis. A p-value $<0.05$ was considered as significant.

\section{Results}

One hundred cases of acute Upper gastrointestinal haemorrhage was systematically observed by Rockall score pre endoscopically and post endoscopically to predict risk of rebleeding and mortality. Patient with Chronic UGIH, coagulation disorder, sepsis, contraindication to endoscopy and patients who did not give consent were excluded from the study. The results of present study are as follows.

Table I shows mean age was found $45.12 \pm 14.9$ years. Male to female ratio was 4:1. Majority $26.0 \%$ patients were service holder. More than ninety percent patients were married. Almost half (48.0\%) the patients were educated at primary level. Half (50.0\%) of the patients were low income group family.

Table II shows patients presented with combined haematemesis and melaena in $61(61.0 \%)$ cases, and $72(72.0 \%)$ patients could arrive in hospital in less than $<24$ hour.
Table I

Socio characteristics of the study population

\begin{tabular}{|c|c|c|}
\hline Socio characteristics & $\begin{array}{c}\text { Number of } \\
\text { patients }\end{array}$ & Percentage \\
\hline \multicolumn{3}{|l|}{ Age (in year) } \\
\hline$\leq 20$ & 6 & 6.0 \\
\hline $21-30$ & 14 & 14.0 \\
\hline $31-40$ & 20 & 20.0 \\
\hline $41-50$ & 31 & 31.0 \\
\hline $51-60$ & 16 & 16.0 \\
\hline $61-70$ & 8 & 8.0 \\
\hline $71-80$ & 4 & 4.0 \\
\hline$>80$ & 1 & 1.0 \\
\hline Mean $\pm \mathrm{SD}$ & 45.12 & \pm 14.9 \\
\hline Range (min-max) & $(18$ & $-82.0)$ \\
\hline \multicolumn{3}{|l|}{ Sex } \\
\hline Male & 80 & 80.0 \\
\hline Female & 20 & 20.0 \\
\hline \multicolumn{3}{|l|}{ Occupation } \\
\hline Service & 26 & 26.0 \\
\hline Business & 19 & 19.0 \\
\hline Labour & 6 & 6.0 \\
\hline Cultivator & 14 & 14.0 \\
\hline House Wife & 18 & 18.0 \\
\hline Retired & 9 & 9.0 \\
\hline Others & 8 & 8.0 \\
\hline \multicolumn{3}{|l|}{ Marital status } \\
\hline Marred & 91 & 91.0 \\
\hline Unmarred & 9 & 9.0 \\
\hline \multicolumn{3}{|l|}{ Education status } \\
\hline Illiterate & 25 & 25.0 \\
\hline Primary & 48 & 48.0 \\
\hline Secondary & 23 & 23.0 \\
\hline Graduate & 4 & 4.0 \\
\hline \multicolumn{3}{|l|}{ Income } \\
\hline Low & 50 & 50.0 \\
\hline Middle & 36 & 36.0 \\
\hline High & 14 & 14.0 \\
\hline
\end{tabular}

Table II

Presentation and hospital arrival duration

\begin{tabular}{lcc}
\hline $\begin{array}{l}\text { Haematemesis / } \\
\text { Melaena }\end{array}$ & $\begin{array}{c}\text { Number of } \\
\text { patients }\end{array}$ & Percentage \\
\hline Haematemesis & 18 & 18.0 \\
Melaena & 21 & 21.0 \\
Both Haematemesis & 61 & 61.0 \\
and Melaena & & \\
Hospital arrival Duration & & 72.0 \\
$<24$ Hour & 72 & 28.0 \\
$>24$ Hour & 28 & \\
\hline
\end{tabular}


Table III

Comorbidity in study population

\begin{tabular}{lcccc}
\hline & $\begin{array}{c}\text { Number of } \\
\text { patients }\end{array}$ & Percentage & \multicolumn{2}{c}{$95 \%$ CI } \\
\hline Hepatic Encephalopathy & 4 & 4.0 & 0 & Lower \\
Chronic Liver disease & 2 & 2.0 & 0 & 8.4 \\
Hepato cellular carcinoma & 2 & 2.0 & 0 & 5.2 \\
Gall stone & 1 & 1.0 & 0 & 5.2 \\
Gastric Carcinoma (Ca) & 1 & 1.0 & 0 & 3.3 \\
Gastric Ca with Metastasis & 3 & 3.0 & 0 & 3.3 \\
Gastrojejunostomy & 1 & 1.0 & 0 & 6.9 \\
Diabetes Mellitus(DM) & 8 & 8.0 & 1.86 & 3.3 \\
DM with coma & 1 & 1.0 & 0 & 14.1 \\
DM+DKA+Hypertension(HTN) & 1 & 1.0 & 0 & 3.3 \\
DM+Arthritis & 1 & 1.0 & 0 & 3.3 \\
DM+HTN & 1 & 1.0 & 0 & 3.3 \\
DM+HTN+Chronic Kidney Disease & 1 & 1.0 & 0 & 3.3 \\
HTN & 3 & 3.0 & 0 & 3.3 \\
HTN+Myocardial infarction(MI) & 1 & 1.0 & 0 & 3.3 \\
Pneumonia & 1 & 1.0 & 0 & 3.3 \\
COPD* & 1 & 1.0 & 0 & 3.3 \\
COPD+IHD** & 1 & 1.0 & 0 & 3.3 \\
Br.Ca+RA+Abdominal perforation & 1 & 1.0 & 0 & 3.3 \\
Rheumatoid arthritis(RA) & 1 & 1.0 & 0 & 3.3 \\
RA+Acute liver failure(ALF) & 1 & 1.0 & 0 & 3.3 \\
Arthritis+HTN & 1 & 1.0 & 0 & 3.3 \\
Connective Tissue Disease & 2 & 2.0 & 0 & 5.2 \\
Arthritis+Renal Failure & 1 & 1.0 & 0 & 3.3 \\
Arsenicosis & 1 & 1.0 & 0 & 3.3 \\
No Comorbidity & 58 & 58.0 & 48.14 & 65.9 \\
\hline
\end{tabular}

COPD* - Chronic obstructive pulmonary disease, IHD** - Ischaemic heart disease.

Table III shows that comorbidity was present in 42 cases.Most of the cases were DM $13(13.0 \%)$ followed byHTN $8.0 \%$ cases.

Table IV

Distribution of the study population by Drug intake, Tobacco and Alcohol consumption

\begin{tabular}{lcccc}
\hline & $\begin{array}{c}\text { Number of } \\
\text { patients }\end{array}$ & Percentage & \multicolumn{2}{c}{ L5\%CI } \\
\hline Drug history & & & & Upper \\
NSAID intake & 13 & 13.0 & 6.0 & 20.0 \\
No drug history & 87 & 87.0 & 80.0 & 94.0 \\
Tobacco & & & & \\
Smoker & 19 & 19.0 & 10.12 & 27.9 \\
Ex smoker & 23 & 23.0 & 15.47 & 30.5 \\
Tobacco leaf chewing & 2 & 2.0 & 0 & 5.2 \\
No tobacco & 56 & 56.0 & 44.77 & 67.2 \\
Alcohol & 4 & & & \\
Alcoholic & 2 & 4.0 & 0 & 8.4 \\
Ex alcoholic & 94 & 9.0 & 0 & 5.2 \\
Non alcoholic & & 94.0 & 88.63 & 99.4 \\
\hline
\end{tabular}

Table IV shows that $13 \%$ patient gave history of NSAID intake prior to illness. Tobacco use was found in $44.0 \%$ patients in the form of present smoker 19(19.0\%), ex- smoker 23(23.0\%) and tobacco leaf chewing $2(2.0 \%)$. Among $6 \%$ alcoholics $4(4.0 \%)$ was continuing and $2(2.0 \%)$ was ex-alcoholic. 
Table V: Distribution of the study population by associated clinical feature

\begin{tabular}{|c|c|c|c|c|}
\hline \multirow[t]{2}{*}{ Clinical feature } & \multirow{2}{*}{$\begin{array}{c}\text { Number of } \\
\text { patients }\end{array}$} & \multirow[t]{2}{*}{ Percentage } & \multicolumn{2}{|c|}{$95 \% \mathrm{CI}$} \\
\hline & & & Lower & Upper \\
\hline \multicolumn{5}{|l|}{ Anaemia } \\
\hline Present & 74 & 74.0 & 64.07 & 83.9 \\
\hline Absent & 26 & 26.0 & 16.07 & 35.9 \\
\hline \multicolumn{5}{|l|}{ Pulse } \\
\hline$>100$ & 29 & 29.0 & 21.0 & 38.0 \\
\hline 61- 99 & 67 & 67.0 & 57.0 & 75.0 \\
\hline $60 /<60$ & 3 & 3.0 & 0 & 7.0 \\
\hline Absent & 1 & 1.0 & 0 & 7.0 \\
\hline Mean \pm SD & \multicolumn{2}{|c|}{$88.41 \pm 15.7$} & & \\
\hline Range $(\min , \max )$ & \multicolumn{2}{|c|}{$60,120.0$} & & \\
\hline \multicolumn{5}{|l|}{ Systolic BP } \\
\hline$\leq 100$ & 52 & 52.0 & 42.0 & 62.0 \\
\hline $100-140$ & 43 & 43.0 & 33.0 & 53.0 \\
\hline$>140$ & 5 & 5.0 & 1.0 & 10.0 \\
\hline Mean \pm SD & \multicolumn{2}{|c|}{$104.5 \pm 22.8$} & & \\
\hline Range (min-max) & \multicolumn{2}{|c|}{$40-210.0$} & & \\
\hline \multicolumn{5}{|l|}{ Diastolic BP } \\
\hline$\leq 60$ & 42 & 42.0 & 32.0 & 51.0 \\
\hline $61-90$ & 56 & 56.0 & 47.0 & 66.0 \\
\hline$>90$ & 2 & 2.0 & 0 & 5.0 \\
\hline Mean \pm SD & \multirow{2}{*}{\multicolumn{2}{|c|}{$\begin{array}{c}66.86 \pm 12.8 \\
20-110.0\end{array}$}} & & \\
\hline Range (min-max) & & $20-110.0$ & & \\
\hline
\end{tabular}

Table $\mathrm{V}$ shows that $74(74.0 \%)$ had anaemia clinically, normal pulse $(60-100 \mathrm{~min})$ was found in $67(67.0 \%)$ cases, while tachycardia in $29(29 \%)$ and bradycardia in $3(3 \%)$ cases. More than half $(52.0 \%)$ patients had low systolic blood pressure (<100 $\mathrm{mmHg}$ ) and Low (d"60 mmHg) diastolic blood pressure was found 42(42.0\%)

Table VI

Distribution of the study patients by CLD features $(n=100)$

\begin{tabular}{lcccc}
\hline CLD features & $\begin{array}{c}\text { Number of } \\
\text { patients }\end{array}$ & Percentage & \multicolumn{2}{c}{$95 \%$ CI } \\
\hline General stigmata & 3 & 3.0 & 0 & Upper \\
Ascites & 7 & 7.0 & 2.0 & 7.0 \\
Ascites+splenomegaly & 2 & 2.0 & 0 & 12.0 \\
Ascites+jaundice & 2 & 2.0 & 0 & 5.0 \\
Ascites+hepatomegaly & 1 & 1.0 & 0 & 5.0 \\
Hepatic encephalopathy & 2 & 2.0 & 0 & 3.0 \\
HE*+Splenomegaly & 1 & 1.0 & 0 & 5.0 \\
HE+hepatosplenomegaly & 2 & 2.0 & 0 & 3.0 \\
Hepatomegaly & 2 & 2.0 & 0 & 5.0 \\
Splenomegaly & 8 & 8.0 & 3 & 5.0 \\
Hepatoslenomegaly & 2 & 2.0 & 0 & 14.0 \\
Hepatosplenomegaly+jaundice & 1 & 1.0 & 0 & 5.0 \\
Jaundice & 1 & 1.0 & 0 & 3.0 \\
No CLD feature & 66 & 66.0 & 57.0 & 4.0 \\
\hline
\end{tabular}

$\mathrm{HE}^{*}$ - Hepatic Encephalopathy.

Table VI shows that CLD features was found in 34(34.0\%) clinically. among them 8(8.0\%) had only Splenomegaly and $7(7.0 \%)$ had ascites. 
Table VII

Endoscopic findings in study population

\begin{tabular}{lcccc}
\hline Endoscopic findings & $\begin{array}{c}\text { Number of } \\
\text { patients }\end{array}$ & Percentage & \multicolumn{2}{c}{$95 \% \mathrm{CI}$} \\
\hline Oesophageal varix & 25 & 25.0 & 17.0 & Upper \\
Oesophageal Ulcer & 2 & 2.0 & 0 & 34.0 \\
Oesophageal+gastric varix & 17 & 17.0 & 10.0 & 25.0 \\
Oesophageal varix+DU* & 4 & 4.0 & 0 & 8.0 \\
GU** 12 & 12.0 & 6.0 & 18.0 & \\
Gastric carcinoma & 6 & 6.0 & 2.0 & 11.0 \\
Gastric erosion & 7 & 7.0 & 2.0 & 12.0 \\
DU 14 & 14.0 & 8.0 & 21.0 & \\
Duodenal polyp & 1 & 1.0 & 0 & 4.0 \\
Normal & 6 & 6.0 & 2.0 & 11.0 \\
No endoscopy done & 6 & 6.0 & 2.0 & 11.0 \\
\hline
\end{tabular}

DU*- Duodenal Ulcer; GU* - Gastric Ulcer.

Table VII shows endoscopically oesophageal varix was found in 25(25.0\%)patients followed by combined oesophageal and gastric varix having $17 \%$ cases and duodenal ulcer in $14.0 \%$ cases. Site of pathology includes Oesophagus $48 \%$ and Gastric pathology involved in $42 \%$ cases. No pathology is found in $6.0 \%$ cases which indicate obscure acute upper GI bleeding.

Table VIII

Endoscopic evidence of bleeding in population

\begin{tabular}{lcc}
\hline $\begin{array}{l}\text { Evidence of } \\
\text { bleeding }\end{array}$ & $\begin{array}{c}\text { Number of } \\
\text { patients }\end{array}$ & Percentage \\
\hline Adherent clot & 72 & 72.0 \\
Blood in stomach & 10 & 10.0 \\
Bleeding vessel & 7 & 7.0 \\
Normal & 5 & 5.0 \\
No Endoscopy done & 6 & 6.0 \\
\hline
\end{tabular}

Table VIII shows that adherent clot is found in $72(72.0 \%)$ cases.

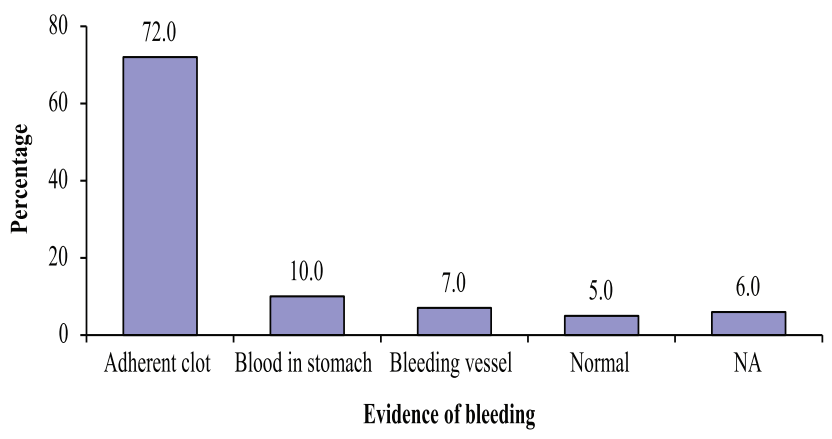

Fig.-1: Bar diagram showing evidence of bleeding of the study patients

Table IX

Distribution of the study population by mode of treatment

\begin{tabular}{lcc}
\hline Mode of treatment & Number of patients & Percentage \\
\hline EVL & 38 & 38.0 \\
Conservative treatment & 62 & 62.0 \\
Blood transfusion & & 12.0 \\
1 unit & 12 & 20.0 \\
2 unit & 20 & 14.0 \\
3 unit & 14 & 10.0 \\
4 unit & 10 & 2.0 \\
5 unit & 6 & 1.0 \\
6 unit & 2 & 1.0 \\
7 unit & 1 & 34.0 \\
8 unit & 1 & 34 \\
No Transfusion & \multicolumn{2}{c}{$4.97 \pm 3.1$} \\
Mean \pm SD & \multicolumn{2}{c}{$1-9$} \\
Range (min-max) & & \\
\hline
\end{tabular}


Table IX shows that EVL was done in 38(38.0\%) cases and 62(62.0\%) cases managed conservatively. Blood transfusion needed in $66 \%$ cases.

Table $\mathbf{X}$

Distribution of the study patients by pre endoscopic $(n=100)$ and post Endoscopic Rockall Score $(n=94)$

\begin{tabular}{|c|c|c|c|c|}
\hline \multirow[t]{2}{*}{ Pre Endoscopic Rockall score } & \multirow{2}{*}{$\begin{array}{c}\text { Number of } \\
\text { patients }\end{array}$} & \multirow[t]{2}{*}{ Percentage } & \multicolumn{2}{|c|}{$95 \% \mathrm{CI}$} \\
\hline & & & Lower & Upper \\
\hline 0 & 15 & 15.0 & 8.0 & 22.0 \\
\hline 1 & 19 & 19.0 & 12.0 & 27.0 \\
\hline 2 & 41 & 41.0 & 31.0 & 51.0 \\
\hline 3 & 14 & 14.0 & 8.0 & 21.0 \\
\hline 4 & 9 & 9.0 & 4.0 & 15.0 \\
\hline 5 & 1 & 1.0 & 0 & 3.0 \\
\hline 6 & 1 & 1.0 & 0 & 4.0 \\
\hline Mean \pm SD & 1.9 & \pm 1.2 & & \\
\hline Range (min-max) & 0 & -6.0 & & \\
\hline \multicolumn{5}{|l|}{ Post Endoscopic Rockall Score } \\
\hline 1 & 3 & 3.0 & 0 & 7.0 \\
\hline 2 & 6 & 6.0 & 2.0 & 11.0 \\
\hline 3 & 11 & 11.0 & 7.0 & 20.0 \\
\hline 4 & 24 & 24.0 & 19.0 & 36.0 \\
\hline 5 & 30 & 30.0 & 21.0 & 40.0 \\
\hline 6 & 13 & 13.0 & 7.0 & 20.0 \\
\hline 7 & 6 & 6.0 & 2.0 & 11.0 \\
\hline 9 & 1 & 1.0 & 0 & 3.0 \\
\hline Not done & 6 & 6.0 & 2.0 & 11.0 \\
\hline Mean \pm SD & \multicolumn{2}{|c|}{$4.83 \pm 1.93$} & & \\
\hline Range (min-max) & \multicolumn{2}{|c|}{$1-9.0$} & & \\
\hline
\end{tabular}

Table X shows that majority 41(410.0\%) patients had 2 pre endoscopic Rockall score and 30(30.0\%) patient had 5 post endoscopic Rockall Score.

Table XI

Distribution of the study population by re-bleeding and outcome

\begin{tabular}{lcccc}
\hline Re-bleeding & $\begin{array}{c}\text { Number of } \\
\text { patients }\end{array}$ & Percentage & Lower & U5\% \\
\hline Present & 89 & 89.0 & 83.0 & 95.0 \\
No & 11 & 11.0 & 5.0 & 17.0 \\
Outcome & & & 83.0 & 94.0 \\
Discharge & 89 & 89.0 & 2.0 & 11.0 \\
Referred & 6 & 6.0 & 1.0 & 10.0 \\
Expired & 5 & 5.0 & & \\
\hline
\end{tabular}

Table XI shows that re-bleeding occurred in 89(89.0\%) cases, discharge could be done in $89(89.0 \%)$ cases, and patient was referred to corresponding centre for treatment of malignancy in $6(6.0 \%)$ case and $5(5.0 \%)$ patient died in hospital. 
Table XII

Distribution of the study population in relation to Presentation, Rebleeding, Pre and Post Endoscopic Rockall Score and Outcome.

\begin{tabular}{|c|c|c|c|}
\hline \multirow[t]{2}{*}{ Presentation } & \multicolumn{3}{|c|}{ Outcome } \\
\hline & Discharge & Referred & Expired \\
\hline Haematemesis & 17 & 1 & 0 \\
\hline Melaena & 19 & 1 & 1 \\
\hline Both Haematemesis and Melaena & 53 & 4 & 4 \\
\hline \multicolumn{4}{|l|}{ Rebleeding } \\
\hline Rebled & 78 & 6 & 5 \\
\hline No Rebleeding & 11 & 0 & 0 \\
\hline \multicolumn{4}{|l|}{ Pre Endoscopic Rockall Score } \\
\hline 0 & 14 & 1 & 0 \\
\hline 1 & 19 & 0 & 0 \\
\hline 2 & 37 & 2 & 2 \\
\hline 3 & 13 & 1 & 0 \\
\hline 4 & 9 & 0 & 0 \\
\hline 5 & 0 & 1 & 0 \\
\hline 6 & 0 & 1 & 0 \\
\hline \multicolumn{4}{|l|}{ Post Endoscopic Rockall score } \\
\hline 1 & 3 & 0 & 0 \\
\hline 2 & 6 & 0 & 0 \\
\hline 3 & 11 & 0 & 0 \\
\hline 4 & 23 & 1 & 0 \\
\hline 5 & 28 & 0 & 2 \\
\hline 6 & 10 & 2 & 1 \\
\hline 7 & 5 & 1 & 0 \\
\hline 9 & 0 & 1 & 0 \\
\hline Endoscopy not done & 3 & 1 & 2 \\
\hline
\end{tabular}

Table XII shows that all the five death occurred in relation to melaena alone (1 death) or in combination with haematemesis (4 deaths). The patients did not have rebleeding (11) had no adverse event. It is also observed that $34(34 \%)$ patient's had pre endoscopic Rockall score $<2$ and no death occurred in this score and Same result was found in $44 \%$ patient with Rockall Score $<5$.

Table XIII

Duration of hospital stay in study population.

\begin{tabular}{lcc}
\hline Hospital stay (in days) & Number of patients & Percentage \\
\hline 1-3 days & 26 & 26.0 \\
4-7 days & 50 & 50.0 \\
$>7$ days & 24 & 24.0 \\
Mean \pm SD & 6.36 & \pm 4.5 \\
Range (min-max) & $(1$ & $-22.0)$ \\
\hline
\end{tabular}

Table XIII shows that 50(50.0\%) patients stayed in hospital between 4-7 days and their mean hospital stay duration is $6.36 \pm 4.5$ days. 
Table XIV

ROC curve of pre endoscopic Rockall score and post endoscopic Rockall score for prediction of Re-bleeding.

\begin{tabular}{lcccc}
\hline & Area under the & Pvalue & \multicolumn{2}{c}{ 95\% Confidence interval (CI) } \\
& ROC curve & & Lower bound & Upper bound \\
\hline Pre endoscopic Rockall score & 0.363 & 0.138 & 0.222 & 0.503 \\
Post endoscopic Rockall score & 0.346 & 0.096 & 0.204 & 0.487 \\
\hline
\end{tabular}

Table XIV shows pre endoscopic Rockall score cut off value of e" 1.50 have $54.5 \%$ sensitivity and $32.6 \%$ specificity for identifying the re-bleeding and post endoscopic Rockall score cut off value of e"3.50 have $81.8 \%$ sensitivity and $20.2 \%$ specificity for identifying the re-bleeding.

Table XV

ROC curve of pre endoscopic Rockall score and post endoscopic Rockall score for prediction of mortality.

\begin{tabular}{lcccc}
\hline & Area under the & Pvalue & \multicolumn{2}{c}{ 95\% Confidence interval (CI) } \\
& ROC curve & & Lower bound & Upper bound \\
\hline Pre endoscopic Rockall score & 0.671 & 0.862 & 0.402 & 0.940 \\
Post endoscopic Rockall score & 0.808 & 0.012 & 0.624 & 0.991 \\
\hline
\end{tabular}

Table XV shows pre endoscopic Rockall score cut off value of $\leq 2.50$, with $50.0 \%$ sensitivity and $76.6 \%$ specificity for identifying the morality and post endoscopic Rockall score cut off value of e"5.50, with 83.0\% sensitivity and $78.7 \%$ specificity for identifying the morality.

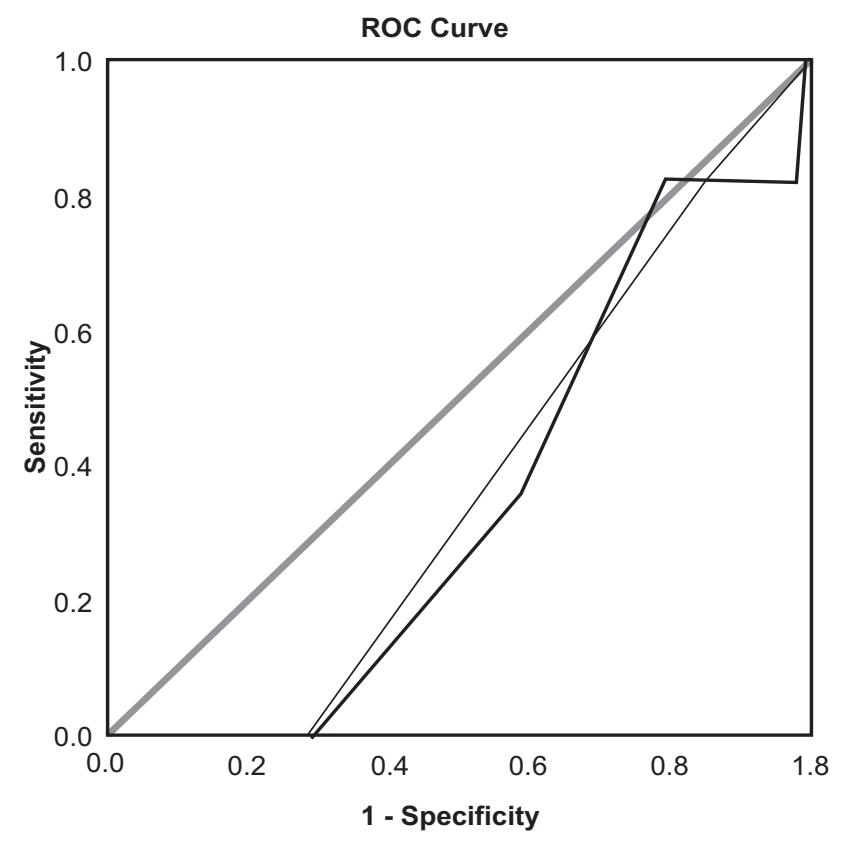

Diagonal segments are produced by ties

Source of the curve

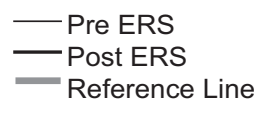

Fig.-2: ROC curve of pre endoscopic Rockall score and post endoscopic Rockall score for prediction of re-bleeding.

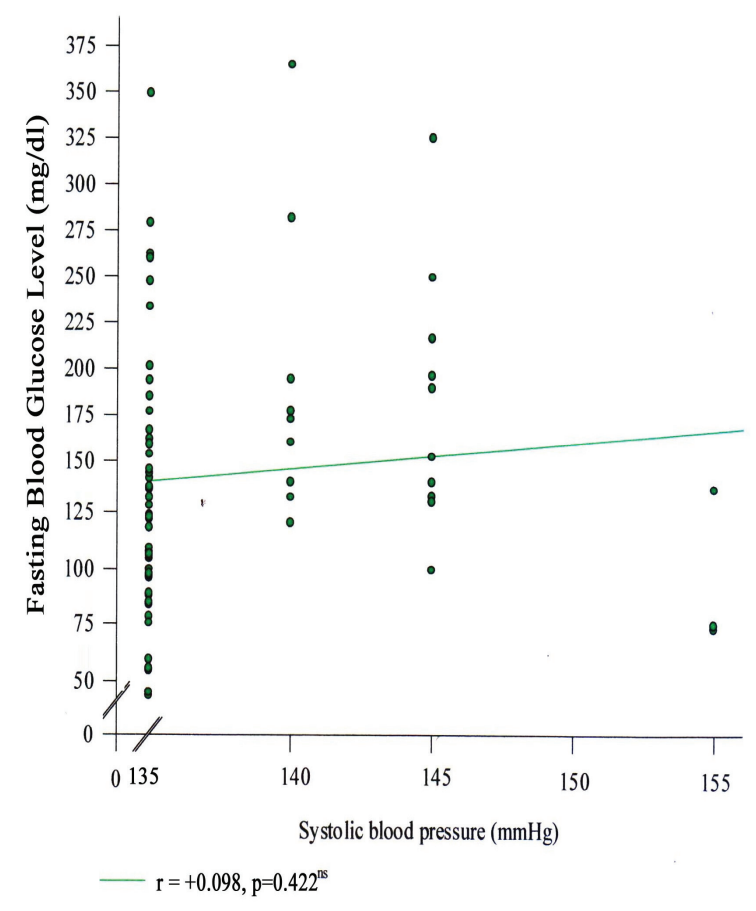

Fig.-3: ROC curve of pre endoscopic Rockall score and post endoscopic Rockall score for prediction of mortality 
Table - XVI

Predictive value of subgroup of Rockall score for rebleeding and Mortality.

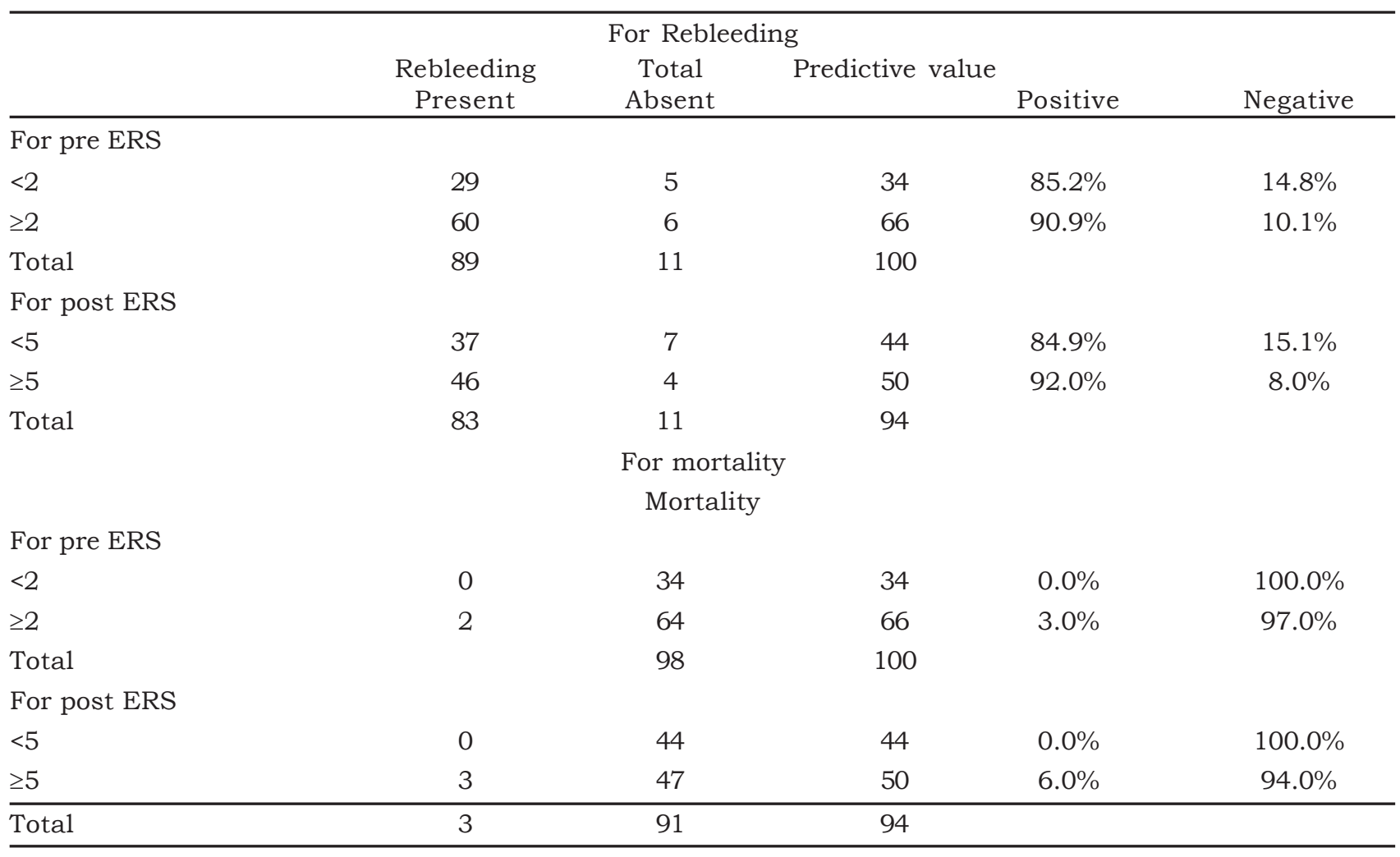

Table XVI shows predictive value for rebleeding and mortality in subgroup of Rockall Score. It was observed that for rebleeding positive predictive value for pre enoscopic Rockall score $<2$ and e-2 are $85.0 \%$ and $90.0 \%$ and for post endoscopic Rockall score $<5$ and $\mathrm{e}-5$ are $84.9 \%$ and $92.0 \%$. it was also observed that for mortality positive predictive value for pre enoscopic Rockall score $<5$ and $\mathrm{e}-5$ are $0.0 \%$ and $3.0 \%$ and for post endoscopic Rockall score $<5$ and $\mathrm{e}-5$ are $0.0 \%$ and $6.0 \%$.

\section{Discussion}

This cross sectional hospital based observational study was carried out with an aim to observe the risk involved in acute upper gastrointestinal haemorrhage by Rockall scoring system, along with etiologic pattern, outcome and the demographic profile of our study population.

Sensitivity and specificity of our study was observed by Receiver Operator Characteristic curve (ROC curve). For re-bleeding pre endoscopic Rockall score cut off value of $\mathrm{e}-1.50$, Area under the ROC curve was 0.363 with $54.5 \%$ sensitivity and $32.6 \%$ specificity and post endoscopic Rockall score cut off value of e-3.5, Area under the ROC curve was 0.346 with
$81.8 \%$ sensitivity and $20.2 \%$ specificity. Blatchford et al. (2000) showed the area under the ROC curve was 0.92 (95\% CI 0.88-0.95), which was significantly higher than that for Rockall admission (0.71 [0.64-0.78]) and our score .363(95\% CI 0.22-0.50) $)^{20}$.

For mortality, in this current series it was observed that receiver-operator characteristic (ROC) gave a pre endoscopic Rockall score cut off value of e-2.5, Area under the ROC curve was 0.671 with $50.0 \%$ sensitivity and $76 \%$ specificity and post endoscopic Rockall score cut off value of e-5.50, Area under the ROC curve was 0.808 with $83.0 \%$ sensitivity and $78.7 \%$ specificity. Rockall et al, found full post endoscopy scores ROC Curve area under curve 0.75 [ (5\% CI $0 \cdot 67-0 \cdot 83]^{15}$. Stanley et al. (2009) reported that admission Rockall score for prediction of intervention or death had Area under the curve was 0.72 [95\% CI 0.68-0.76] and full Rockall scores By ROC curve analysis for prediction of intervention or death (area under the curve was 0.70 [95\% CI 0.65-0.75 $]^{19}$

In present study predictive value for rebleeding and mortality in subgroups of Rockall score was determined. It was observed that for rebleeding positive predictive value for preendoscopic score $<2$ and $\mathrm{e}-2$ are $85.2 \%$ and $90.2 \%$ and for postendoscopic 
Rockall score $<5$ and $\mathrm{e}-5$ are $84.9 \%$ and $92.0 \%$ which is indicative of definitive rebleeding and does not predict difference between preendoscopic and postendoscopic out come. For mortality positive predictive value for preendoscopic score $<2$ and $\mathrm{e}-2$ are $0.0 \%$ and $3.0 \%$ and for postendoscopic Rockall score $<5$ and $\mathrm{e}-5$ are $0.0 \%$ and $6.0 \%$ which indicate poor predictive value for mortality and predict little difference between preendoscopic and postendoscopic out come. In clinical decision making this study reveals when preendoscopic Rockall score is $<2$ and postendoscopic Rockall score < 5 predicts good outcome which is significant.

In this current study, It was observed that pre endoscopic Rockall score started from 0 to 6 as highest score with Mean $1.9 \pm 1 \mathrm{SD}$, among them highest $30.0 \%$ patients had 5 pre endoscopic Rockall score. On the other hand, it was observed that post endoscopic Rockall score Ranged 1 to 9 with Mean $4.83 \pm 1.93 \mathrm{SD}$, highest number $30.0 \%$ patients had 5 endoscopic Rockall score followed by 4 in $25.0 \%$.

In our study outcome observed in relation to Rockall score. Good outcome was observed having pre endoscopic Rockall score $<2$ in 34(34\%) patient's and in $44 \%$ patient $<5$ with postendoscopic Rockall Score. Tommy T. Oei et al defined between 0-1 $(<<2)$ pre endoscopic Rockall Score as low risk group and observed in $26 \%$ cases which are nearly similar to our findings. L. Jensen et al used similar score as cut off value for low risk group and found 26.6\% patient under this group ${ }^{21}$. Dominik Cieniawski et al classified risk group as Rockall score $<3$ as low risk group and found no death at Rockall Score 0-1 which coins same with our study ${ }^{22}$. In case of post endoscopic Rockall score, adverse events was observed at/above score 5. In a 247 patient series study Nicholus I. Church et al found mortality at/ above Rockall score 6, which nearly match our study.

In our study we observed rebleeding in $89 \%$ cases and all the 5 death is observed in case of rebleeding. Rebleeding was observed by Alexander Philip Jacob et al (2004) in 25\% 23 and Daniela Dicu RN (2012) in $40.2 \%$ cases $^{16}$. These results differ from our observation because we defined rebleeding according to Rockall Risk stratification score as any evidence of bleeding occurring after 24 hours of onset; Alexander Philip observed it after 48-72 hours and Daniela Dicu after 60 days.

In this current study it was observed that combined haematemesis and melaena was found in $62.0 \%$ cases, individually haematemesis $17.0 \%$ and melaena $21.0 \%$. Boonpongmanee et al. (2004) obtained in their study that melaena accounted for $56 \%$, followed by haematemesis (31\%); 13\% of patients presented with both haematemesis and melaena; Peter et al. (1999) found that haematemesis was in $40 \%$ to $55 \%$ of patients, melaena in about $70 \%$ to $80 \%$, and hematochezia in about $15 \%$ to $20 \%{ }^{6,24,12}$. Peura et al. found either hematochezia or melaena was found in $90 \%$ to $98 \%$ of patients, which does not match with our results ${ }^{25}$.

In our study outcome in relation to presentation was observed that all the five death occurred in relation to melaena alone $1 \%$ or in combination with haematemesis $4 \%$. The patients died have intimate relationship with melaena.This is a very important finding in our study because for only haematemesis there is no serious adverse event, patient could be managed at primary care level without referring or hospital admission sometimes. In case of melaena patient should be individualized as there is 1 deaths among 21 individual melaena affected patient. When there is both haematemesis and melaena every patient should be hospitalized for proper medical supervision. In Groote Schuur hospital, Cape Town, SZ Kalula, GH Swingler, JA Louw (1997-1998) observed that absence of melaena and absence of syncope was independent predictor of good outcome which support our opinion ${ }^{26}$.

In this present study it was observed that patients with acute upper gastrointestinal bleeding was prime in 5 th decade and the mean age was $45.12 \pm 14.9$ years varied from $18-82$ years. In another study Yang et al. (2006) obtained the mean age was $33.3 \pm 11.0$ years, which is lesser with the present study ${ }^{11}$. And Boonpongmanee et al. (2004) and Kaplan et al. (2001) showed the mean age of the was 62.2 years varied from 19-95 years and 73.3 years varied from 65-100 years, which are higher with the current study, this may be stated that the higher age range maybe due to increased life expectancy, geographical and racial influences that may have significant impacts on acute upper gastrointestinal bleeding ${ }^{3,5}$.

In this series it was observed that male were predominant where male to female ratio was $4: 1$, which is closely resembled with Bayyurt et al. (2007) Boonpongmanee et al. (2004) studies $^{10,3}$. In another study, Kaplan et al. (2001) found $42 \%$ of the participants were male and $58.0 \%$ were female ${ }^{5}$. it differs with our study because this study was done in cardiovascular health study setting hospitalized older patients. It was observed that more than one fourth $(26.0 \%)$ of the patients were service holder and female patients mostly (18.0\%) housewife. More than ninety percent $(91.0 \%)$ patients were married. Kaplan et al. (2001) found that 66.0\% married, which 
is comparable with the current study ${ }^{5}$. Almost a half $(48.0 \%)$ of the patients was educated at primary level and $50.0 \%$ of the patients came from low income family.

Comorbid illness predicts mortality in upper gastrointestinal bleeding obtained by Jiranek and Kozarek (1996) ${ }^{2}$. The number of different organs with disease on admission correlated closely with mortality in a national survey found by Silverstein et al. $1981^{12}$. In this series it was observed that patients presented with comorbidity in 41 cases with 95\% CI 31.4 to $50.6 \%$. Among the comorbidity the highest number of cases was DM with its complication and associated disease involving in $10(10.0 \%)$ cases. Kaplan et al. (2001) found diabetes mellitus $9.0 \%$ in their study patients which match our results ${ }^{5}$. HTN associated with $8.0 \%$ patients.

In this present study it was observed that NSAID intake was found in $14.0 \%$ cases. Boonpongmanee et al. (2004) found $42.9 \%$ NSAID in their study patients ${ }^{3}$. In this present study it was observed that tobacco use was found in $44.0 \%$ patients with current smoker $19.0 \%$ and alcoholic $4.0 \%$. Kaplan et al. (2001) showed current smoker $12.0 \%$ and more than a half $(51.0 \%)$ of their patients was alcoholic respectively, differing our study due to cultural background ${ }^{5}$.

In this current study it was observed that tachycardia $(>100 / \mathrm{min})$ is found in $29 \%$ cases , More than half $(52.0 \%)$ of the patients had low systolic blood pressure (<100 mmHg) the mean systolic BP was $104.5 \pm 22.8$ $\mathrm{mmHg}$. and Low (d"60 $\mathrm{mmHg}$ ) diastolic blood pressure was found in $42.0 \%$ cases and the mean diastolic blood pressure was $66.86 \pm 12.8 \mathrm{mmHg}$. Kaplan et al. (2001) study found the mean systolic blood pressure $136.7 \mathrm{mmHg}$ varied from 77 to 236 and the mean diastolic blood pressure $70.9 \mathrm{mmHg}$ with varied from 0 to $116 \mathrm{mmHg}$, which is comparable with the current study $^{5}$. Schiller found systolic blood pressure the much more important of the two, with mortality rates of about $8 \%$ for SBP e" $100 \mathrm{~mm} \mathrm{Hg}, 17 \%$ for SBP 80 to $99 \mathrm{~mm} \mathrm{Hg}$, and greater than 30\% for SBP < 80 (Schiller et al. 1970) ${ }^{27}$.

In this series it was observed that CLD stigmata was found in $29 \%$ cases, including Jaundice in $4 \%$ of patients. jaundice is a predictor of increased mortality rate from $9.4 \%$ to $38.2 \%$ when present observed by Peter et al. (1999) ${ }^{6}$.

In this current study Low haemoglobin $(<10 \mathrm{gm} / \mathrm{dl})$ was found in $47.0 \%$. Clinically $74 \%$ patients were anaemic. Peter et al. (1999) mentioned that Rockall found a positive correlation between hemoglobin and both rebleeding and mortality rates ${ }^{6}$. Hemoglobin <
$10 \mathrm{~g} / \mathrm{dL}$ increased the mortality rate from $10.8 \%$ to $18.9 \%$ and the rebleeding rate from $11.7 \%$ to $23.3 \%$ obtained by Rockall et al. (1996) ${ }^{15}$.

In our study after endoscopy predominant single pathology was found oesophageal varix $25.0 \%$, followed by duodenal ulcer $14.0 \%$. Bayyurt et al. (2007) found $18.4 \%$ duodenal ulcer (DU), $4.6 \%$ gastric ulcer (GU) of those underwent upper gastro endoscopy for the last 5 years in evaluation of Endoscopic diagnoses which nearly match our results ${ }^{10}$. Considering site of involvement Oesophageal involvement was found in $48.0 \%$ cases, Gastric pathology $42.0 \%$ and duodenal pathology $14.0 \%$. Endoscopic diagnosis could not be done in $6(6.0 \%)$ cases indicating obscure upper gastrointestinal haemorrhage. Boonpongmanee et al. (2004) observed peptic ulcer $31.8 \%$, varices $19.8 \%$ and mucosal erosive disease $10.3 \%$ were the most common causes of $\mathrm{UGIB}^{3}$. Gastric ulcer was more common than duodenal ulcer (19.8\% vs. $11.9 \%)$. There was no definite source of UGIB in 18 patients in their study which is comparable with our study.

In this present study it patient was managed by EVL in $38.0 \%$ cases and $62.0 \%$ cases managed conservatively. Blood transfusion is needed in $66 \%$ patients ranging from 1 to 9 unit at mean 4.97 unit with $\mathrm{SD} \pm 3.1$. Patients required transfusions in about $50 \%$ to $75 \%$ of cases reported by Peter et al. $(1999)^{6}$.

In this present study it was observed that re-bleeding was found in $89.0 \%$ cases, discharge given in $89.0 \%$, referred to surgery $6.0 \%$ and $5.0 \%$ expired. Palmer, (2007) mentioned that re-bleeding occurs in 15-20\% of cases, usually within the first $24 \mathrm{~h}^{4}$. In this current study it was observed that $50.0 \%$ patients stayed in the hospital for 4-7 days and the mean duration of hospital stay was $6.36 \pm 4.5$ days varied from $1-22$ days. Similarly, Jiranek and Kozarek (1996) found the average length of stay per patient was 6.45 days, which is consistent with the current study ${ }^{2}$.

\section{References}

1. Fallah, MA, Prakash, C \& Edmundowicz, S 2000, 'Acute gastrointestinal bleeding', Med Clin North Am. vol. 84, no. 5, pp. 1183-208.

2. Jiranek, GC \& Kozarek, RA 1996, 'A cost-effective approach to the patient with peptic ulcer bleeding', Surgical clinics of north america vol. 76 , no. 1, pp. 83103.

3. Boonpongmanee, S, Fleischer, DE, Pezzulo, JC, Collier, K, Mayoral, W \& Al-Kawas, F et al. 2004, 'The frequency of peptic ulcer disease as a cause of upper-GI bleeding is exaggerated', Gastrointest Endosc, vol. 59, no. 7, pp. 788-94. 
4. Palmer, K2007, 'Acute upper gastrointestinal haemorrhage', Br Med Bull, vol. 83, pp. 307-24.

5. Kaplan, RC, Heckbert, SR \& Koepsell, TD 2001, 'Risk factors for gastrointestinal bleeding among older patients. Cardiovascular Health Study Investigators', J Am Geriatr Soc. vol. 49, no. 2, pp. 126-33.

6. Peter, DJ \& Doughtery, JM 1999, 'Evaluation of the patient with gastrointestinal bleeding: an evidence based approach', Emerg Med Clin North Am, vol. 17, no. 1, pp .239-61.

7. Yavorski, RT, Wong, RK \& Maydonovitch, C 1995, 'Analysis of 3,294 cases of upper gastrointestinal bleeding in military medical facilities', Am J Gastroenterol, vol. 90, no. 4, pp.568-73.

8. Lewis, JD, Shin, EJ \& Metz, DC 2000, 'Characterization of gastrointestinal bleeding in severely ill hospitalized patients', Crit Care Med, vol. 28, no. 1, pp.261-2.

9. Longstrech, GF 1995, 'Epidemiology of hospitalization for acute upper gastrointestinal hemorrhage: a population based study', Am J Gastroenterol, vol. 90, no. 2, pp.206-10.

10. Bayyurt, N, Abasiyanik, MF, Sander, E \& Salih, BA 2007, 'Canonical analysis of factors involved in the occurrence of peptic ulcers', Dig Dis Sci. vol. 52, no. 1, pp. 140-6.

11. Yang, CS, Lee, WJ, Wang, HH, Huang, SP, Lin, JT \& Wu, MS 2006, 'Spectrum of endoscopic ûndings in patients with upper gastrointestinal symptoms after laparoscopic bariatric surgery', Obes Surg, vol. 16, no. 9, pp. 1232-7.

12. Silverstein, FE, Gilbert, DA \& Tedesco, FJ 1981, 'The National ASGE survey on upper gastrointestinal bleeding: 1. Study design and baseline data', Gastrointest Endosc. Vol. 27, no. 2, pp. 73-9.

13. Cappell, MS \& Abdullah, M 2000, 'Management of gastrointestinal bleeding induced by gastrointestinal endoscopy', Gastroenterol Clin North Am. vol. 29, no. 1, pp. 125-67.

14. Dworzynski, K 2012, 'Management of acute upper gastrointestinal bleeding: summary of NICE guidance', $B M J$, vol. 344, p.e3412.

15. Rockall, TA, Logan, RF, Devlin, HB \& Northfield, TC 1996, 'Risk assessment after acute upper gastrointestinal haemorrhage', Gut, vol. 38, pp. 31621.

16. Daniela Dicu RN, Msc a, Felicia Pop RN, MSc b, Daniela Ionescu MD, PhDc,d,N , Tiberius Dicu PhD, 'Comparison of risk scoring systems in predicting clinical outcome at upper gastrointestinal bleeding patients in an emergency unit, American Journal of Emergency Medicine (2013) 31, pp. 94-99

17. Shahid Sarwar, Anwaar Ahmed Khan* and Shandana Tarique, 'Comparison of MELD, Child Pugh Score and Rockall Score for Predicting
Rebleeding and In-Hospital Mortality in Patients of Variceal Bleeding Journal of the College of Physicians and Surgeons Pakistan 2008, Vol. 18 (8), pp. 524-525.

18. Tommy T. Oei, M.D., Gareth S. Dulai, M.D, Ian M. Gralnek, M.D., M.S.H.S., Dong Chang, M.D., Amy M. Kilbourne, Ph.D., and Gwen Alofaituli Sale, M.S, 'Hospital Care for Low-Risk Patients With Acute, Nonvariceal Upper GI Hemorrhage: A Comparison of Neighboring Community and Tertiary Care Centers' THE AMERICAN JOURNAL OF GASTROENTEROLOGY Vol. 97, No. 9, 2002, pp. 2271-78.

19. Stanley, AJ, Ashley, D, Dalton, HR, Mowat, C, Gaya, DR \& Thompson, E et al. 2009, 'Outpatient management of patients with low-risk uppergastrointestinal haemorrhage: Multicentre validation and prospective evaluation', Lancet, vol. 373, pp. $42-7$.

20. Blatchford, O, Murray, WR \& Blatchford, M 2000, 'A risk score to predict need for treatment for uppergastrointestinal haemorrhage', Lancet vol. 356, pp.1318-21.

21. L. Jansen, P. Leffers, M. Hermans, P. Stassen, A. Masclee, Y. Keulemans, 'Identification of patients with upper gastrointestinal bleeding who do not need, immediate treatment, The Netherlands Journal of Medicine, September 2011, vol.69, no. 9, pp 384-88.

22. Dominik Cieniawski, Ewelina Kuzniar, Marek Winiarski, Maciej Mat at Bok, Wojciech Kostarc, MichaB P'dziwiatr iwiatr, 'Prognostic value of the Rockall score in patients with acute nonvariceal bleeding from the upper gastrointestinal tract' Przegl ${ }^{1} d$ Lekarski 2013 / 70 / 13.

23. Alexander Philip Jacob, Vui Heng Chong, Aza Zetty Feroena Jamaludin, Anand Jalihal, Maliackal John Alexander, "Clinical presentations and outcomes of patients with non-variceal upper gastrointestinal bleeding requiring endoscopic therapy, Brunei Darussalam Journal of Health Volume 2, 2007, pp. 31-38.

24. Longstreth, GF \& Feitelberg, SP 1994, 'Hospital care of acute nonvariceal upper gastrointestinal bleeding: 1991 versus 1981', J Clin Gastroenterol. Vol. 19, p. 189.

25. Peura, DA, Lama, FL \& Goustout, CJ 1997, 'The American College of Gastroenterology Bleeding Registry: Preliminary findings', Am J Gastroenterol vol. 92, p. 924.

26. SZ Kalula, GH Swingler, JALouw, Clinical predictors of outcome in acute upper gastro-intestinal bleeding : SAMJ , April 2003, Vol. 93, No. 4

27. Schiller, KFR, Truelove, SC, Williams, DG 1970, 'Hematemesis and melaena with special reference to factors influencing the outcome', $\mathrm{Br}$ Med $J$ vol. 27, p. 1970. 